\title{
A Case Study of Clinical Mastitis in a Cow
}

\author{
B. R. Babji*, G. Abhinav Kumar Reddy, G. Ambica and S. Ranjith Kumar \\ Department of Veterinary Medicine, PVNR TVU Rajendranagar, Hyderabad, India \\ *Corresponding author
}

\section{A B S T R A C T}

K e y w o r d s
Cow, Mastitis,
Haematology,
Antibiotic
sensitivity test and
Treatment

A four years age cow was presented to the Veterinary Clinical Complex (VCC), College of Veterinary Science, Rajendranagar, Hyderabad with the history of decreased appetite, depression, decreased milk yield and with swollen mammary gland for four days. General clinical examination revealed increased body temperature of $104^{0} \mathrm{~F}$ and palpation of udder revealed swollen udder and animal is feeling pain on touch. Milk was stripped for testing and found flakes and the colour of the milk is yellowish brown. Complete blood examination showed increased total erythrocyte count and neutrophils, and decreased concentration of lymphocytes. Further milk sample was tested for cultural and antibiotic sensitivity test and was diagnosed as clinical mastitis developed due to Staphylococcus aureus. Treatment with both topical and parenteral administration of anti-inflammatory, antibiotics and other supportive drugs was given for seven days continuously and cow recovered completely with alleviation of clinical signs and normal milk secretion.

\section{Introduction}

Mastitis is one of the most important economical diseases of dairy cattle (Bramley, 1992) $)^{1}$.Generally, the clinical form of mastitis divided into mild, moderate or severe. In mild cases, visible abnormality is limited to the milk only i.e. clots, flakes or watery milk. If cows are not fore-stripped before the milking unit is attached, mild clinical mastitis will go unnoticed. In the case of moderate clinical mastitis, both milk and udder show abnormalities. In severe cases milk, udder, and cow are affected (Ganguly, 2014).
The animal may have a fever, off-feed, depressed, and down. Severe clinical mastitis is often called acute mastitis. Generally, the mastitis is produced by a variety of gram positive and negative bacterial species and is characterized by inflammation of parenchyma of the mammary gland with physical, chemical and bacteriological changes in the milk and pathological changes in the grandular tissues (Radostits et al., 2007). It is also defined as inflammation of mammary gland or udder tissue parenchyma which is caused by bacteria and its toxins (Sharma et al., 2006). 
The bacterial contamination of milk from affected cows render it unfit for human consumption and provide a mechanism of spread of diseases like tuberculosis, sorethroat, Q-fever, brucellosis, leptospirosis etc. and has zoonotic importance (Sharif et al., $2009)^{5}$.Usually there are two ways to classify cases of mastitis. Environmental and contagious pathogens are spread cow-to-cow, typically during milking as infected mammary glands serve as the primary reservoir for such microbes. Contagious pathogens include Staphylococcus aureus, Streptococcus agalactiae, and Mycoplasma Spp. (Gallin et al., 1992). Environmental pathogens are those which primarily reside in the cow's normal habitat. Cows are primarily exposed to these pathogens between milkings when teat ends come in contact with contaminated bedding, manure, contaminated water, or soil. Common environmental pathogens include Escherichia coli, Klebsiella spp., and environmental streptococci such as $S$. uberis and S. dysgalactiae (Smith et al., 1985). There are many other microorganisms that have been isolated from cases of mastitis and are associated with the cow's environment.

\section{Materials and Methods}

A four years age cow was presented to the Veterinary Clinical Complex (VCC), College of Veterinary Science, Rajendranagar, Hyderabad with the history of decreased appetite, depression, decreased milk yield and with swollen mammary gland for the last four days. General clinical examination was done and found increased body temperature of $104^{0} \mathrm{~F}$ and also mild increase in heart rate and respiratory rate. Palpation of udder revealed swollen udder and animal is feeling pain on touch. Milk was stripped on a tray with black back ground to fing flakes and change in colour. Milk also tested for $\mathrm{pH}$ using $\mathrm{pH}$ strips placed in the milk sample and compared with the calibrator papers. Some amount of milk was collected under sterile condition in a test tube and tested at Department of Veterinary Microbiology, College of Veterinary Science, Rajendranagar, Hyderabad. Cultural examination was done on Mannitol salt agar (MSA) having high salt condition where only Staphylococcus aureus can survive; and also tested for specific bacteria Gram's staining was done. Antibiotic sensitivity testing was done with antibiotic discs of Streptomycin (S10), Ampicillin (Amp10), Oflaxacin (OF2), Ceftriaxone (CTR), Enrofloxacin (EX5) and Ciprofloxacin(CIP5) placed on Muller Hinton Agar (MHA) plates with definite distance and incubate for 24hrs. Blood sample also collected for complete analysis and processed in diagnostic laboratory, Department of Veterinary Clinical Complex, College of Veterinary Science, Hyderabad.

\section{Results and Discussion}

Milk stripped on tray with black back ground revealed presence of flakes with yellowish brown dicolouration of milk (Fig. 1) and milk $\mathrm{pH}$ was in the range of 7-8 (Fig. 2). Culture of milk on Mannitol salt agar (MSA) resulted in growth of golden yellow coloured staphylococcal colonies (Fig. 3) and Gram's staining was done for confirmation staphylococcus organisms (Fig. 4). Complete blood analysis revealed increased total erythrocyte count and neutrophils, and decreased concentration of lymphocytes (Table 1).

By clinical signs, consistency and $\mathrm{PH}$ of milk and cultural examination the case was diagnosed as clinical mastitis. Antibiotic sensitivity test showed more sensitive to Ceftriaxone (Fig. 5). Hence, accordingly, treatment was started with Inj.GARD PLUS (Cefaperazone + Sulbactum)given 1 gm for7 daysgiven I/M and other medication with Inj. Flunixinemeglumine15 $\mathrm{ml} \quad \mathrm{I} / \mathrm{M}, \quad \mathrm{Inj}$. Anistamine $15 \mathrm{ml} \mathrm{I/M}$, Inj.Toxol- $20 \mathrm{ml} \mathrm{I} / \mathrm{M}$ given for 5 days. One dose of Inj. Intavita 
(Vitamin $\mathrm{A}, \mathrm{D}_{3}$ and E) $5 \mathrm{ml}$ given deep $\mathrm{I} / \mathrm{M}$ once. Applied topical Wisprecointment over udder and also given oral Uddo care powder BID as oral Nutrition @ 50g daily P/O for 7 days (Fig. 6). Cow started showing response from second day onwards has recovered completely after seven days of treatment with improvement in health condition and milk yield without flakes, normal colour and $\mathrm{pH}$ (Fig. 7).

Mastitis in dairy cow is a highly prevalent infectious disease, causing considerable economic loss worldwide (Halasa et al., 2007; Rajala et al., 1999). Generally Mild mastitis can often disappear in a few days with no treatment or with massage and hand stripping of the quarter (Barkema). Mastitis may result in changes in the milk, udder of cow or any combination. Fore milking is the best method of early mastitis detection - clots, flakes, and changes in colour or consistency can be seen when milk is stripped on a dark surface (Politis, 1996). In The main treatment of mastitis is commonly administered by intramammary infusion of an ointment and intramuscular or intravenous injection of antibiotics. Intramammary antibiotics should be the first-line treatment for cows with mild uncomplicated mastitis in a single quarter. Systemic antibiotics should be used when more than one quarter is affected, when udder changes are marked or when the cow is obviously ill. In the present case, as the infection is systemic involving the entire udder we used parenteral antibiotic therapy with a third-generation cephalosporin antibiotic. Supportive therapy given to the present case with Inj. Intavita (Vitamin A, D3 and E) and Mammidium powder (Multi vitamin and mineral) could improve the epithelial health, physical defence barriers of the udder, and alter the quality and quantity of keratin plug and is similar with the earlier findings that $\mathrm{Cu}, \mathrm{Zn}, \mathrm{Se}$, and vitamins $\mathrm{A}$ and $\mathrm{E}$ influence the phagocytic cells functions in cattle and the killing ability of immune cells is shown to be increased by nutritional supplementation with Vitamin E, which has consistently been shown to improve neutrophil function in dairy cows (Politis, 1996) and Mammidium powder helps to recover from mastitis and promote udder good health (Sharif et al., 2009).

Table.1 Haematological Findings

\begin{tabular}{|c|c|c|}
\hline Parameter & Mastitis cow (Present case) & Normal values \\
\hline Hemoglobin(g/dl) & 10.2 & $8.0-15.0$ \\
\hline PCV (\%) & 26 & $24-46$ \\
\hline $\operatorname{RBC}\left(10^{6} / \mu \mathrm{l}\right)$ & 6.2 & 5-10 \\
\hline PCV $(\%)$ & 26 & $24-46$ \\
\hline $\operatorname{WBC}\left(10^{3 /} / \mu \mathrm{l}\right)$ & 8.5 & 4-6 \\
\hline Neutrophils (\%) & 64 & $50-55$ \\
\hline Lymphocytes(\%) & 43 & $60-63$ \\
\hline Monocytes (\%) & 2 & $1-3$ \\
\hline Eosinophils (\%) & 3 & $0-1$ \\
\hline
\end{tabular}




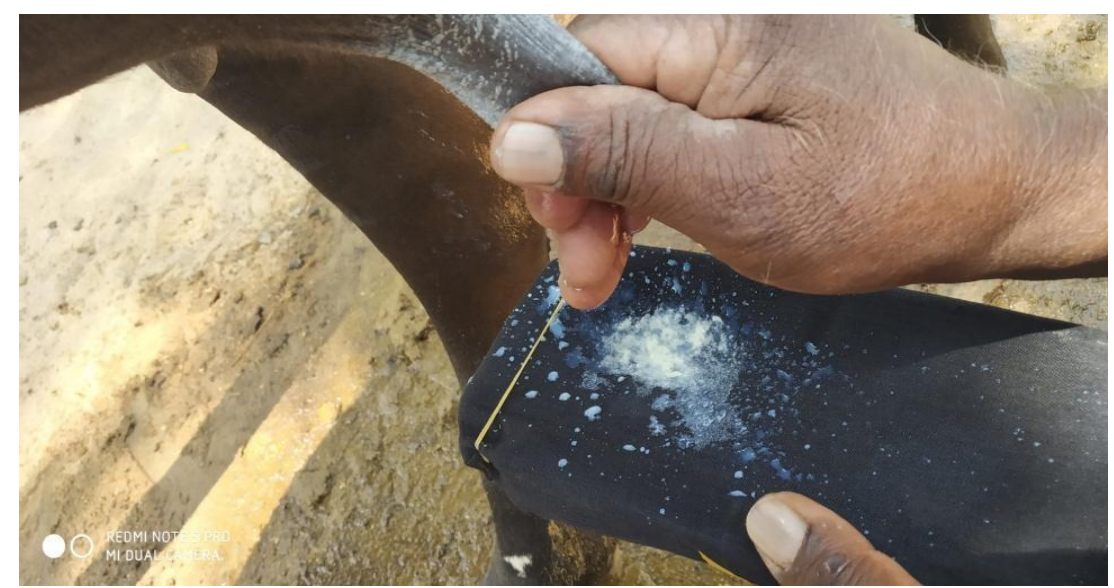

Fig.1 Milk stripped on tray with black back ground showing flakes

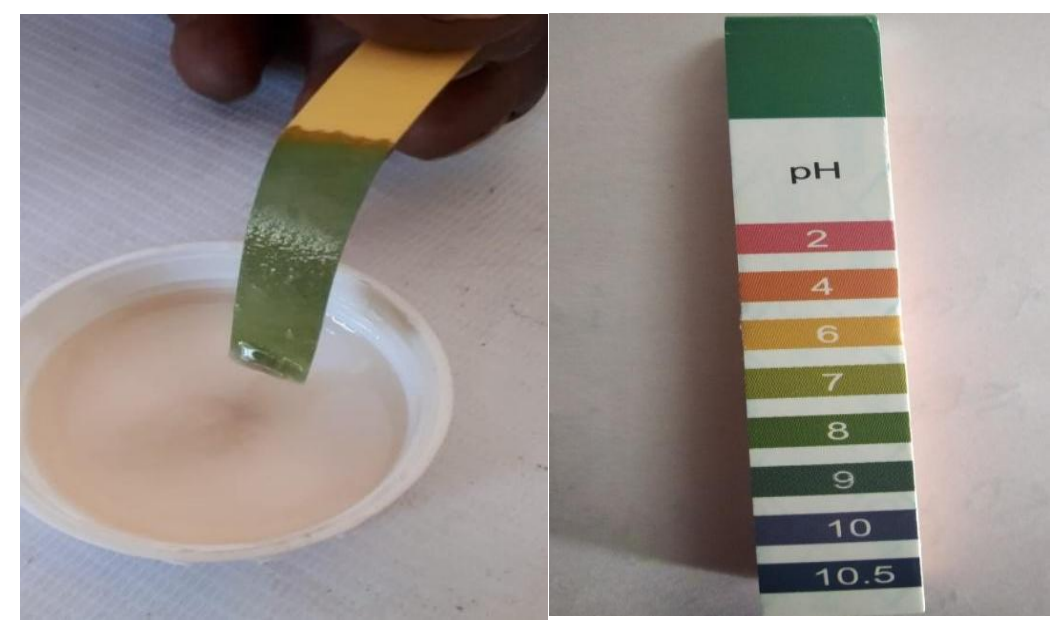

Fig.2 Identifying PH of Milk (Recorded as 7- 8, positive for mastitis)

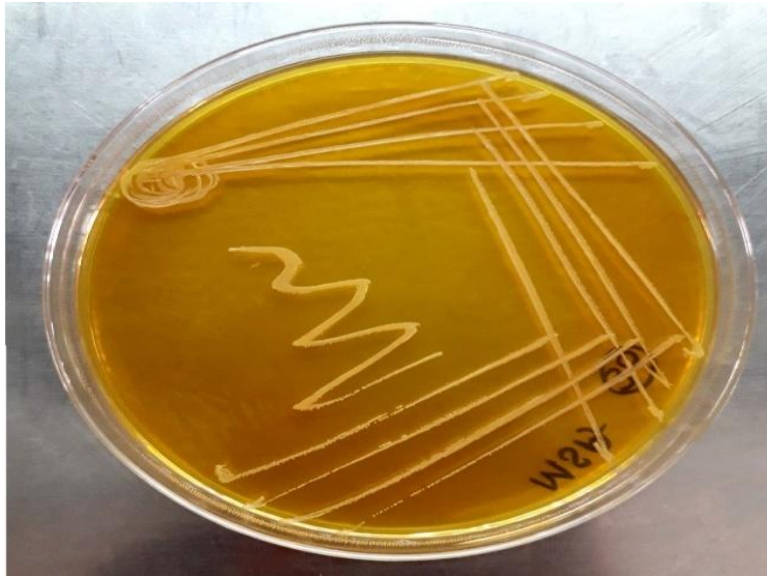

Fig.3 Cultural ExaminationGolden yellow pigment colonies of Staphylococcus

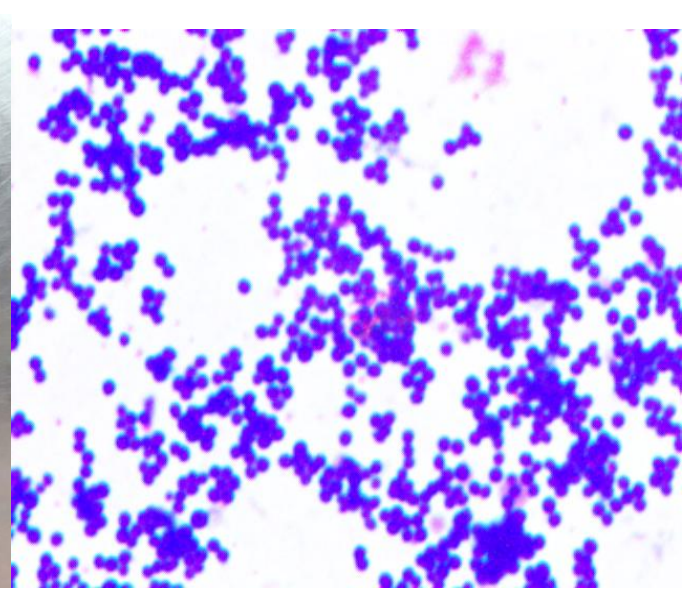

Fig.4 Staphylococcus organisms by Gram staining 


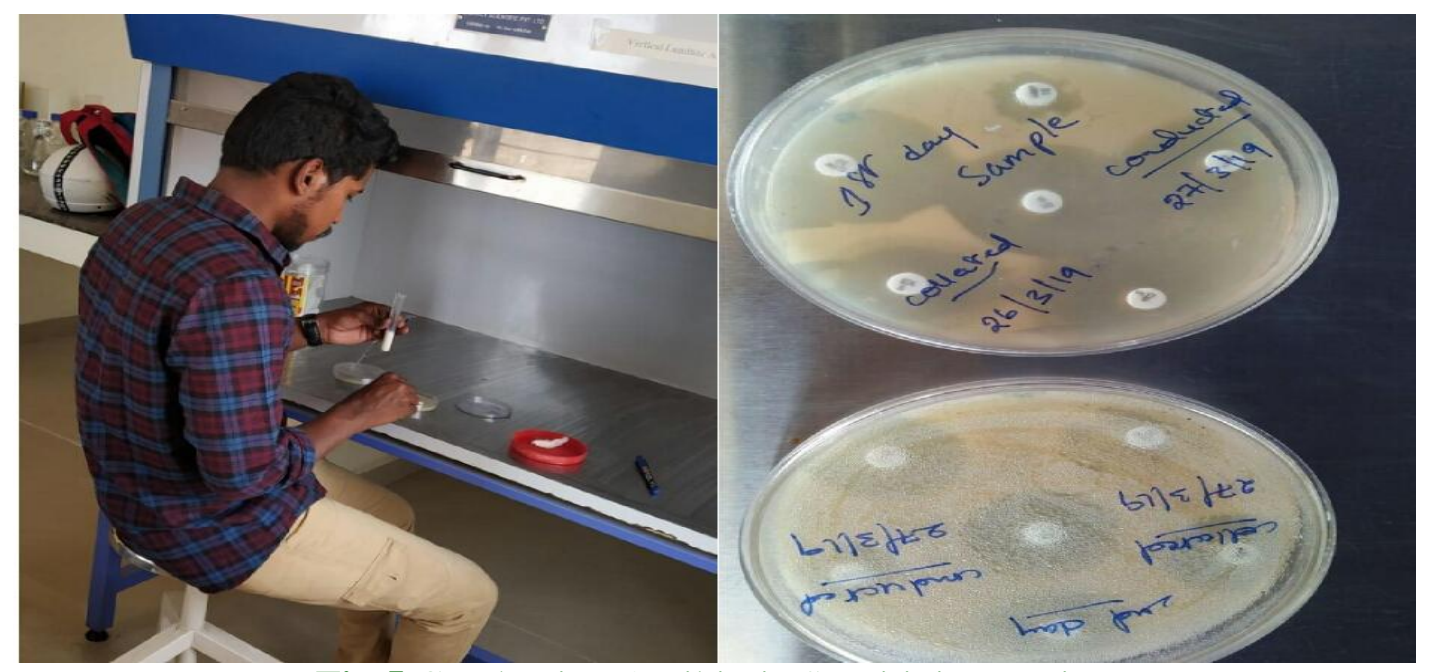

Fig.5 Conducting Antibiotic Sensitivity Testing

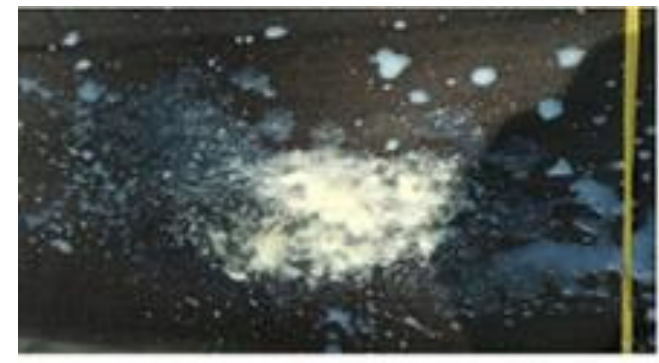

DAY 1

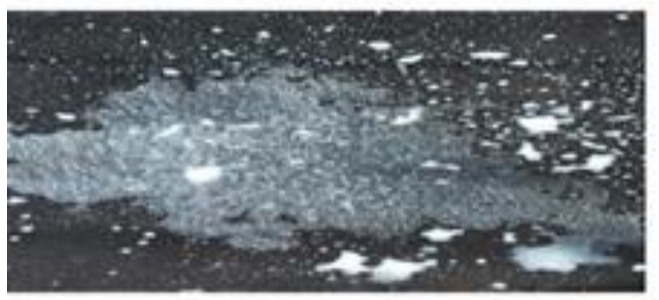

DAY 2

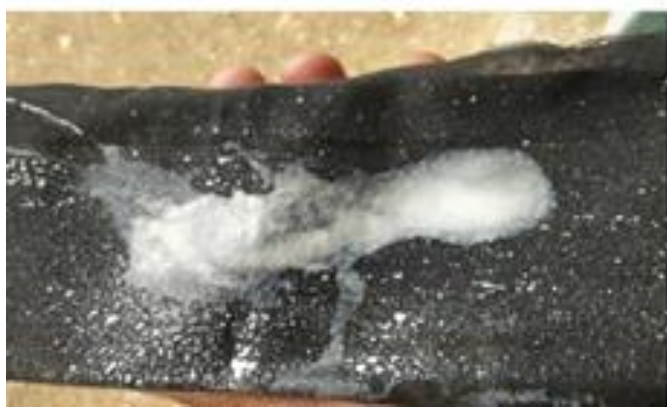

DAY 3

Fig.7 Post-treatment observing of Milk, (Negative for flakes)

With the present findings it can be concluded that change in milk colour and $\mathrm{pH}$ can be considered as cow side tests for diagnosis of mastitis, however, cultural examination reveal the actual and confirmatory diagnosis. Parenteral antibiotic therapy coupled with topical anti-inflammatory medication along with supportive therapy with vitamins and minerals is highly effective in treating multiple quarter mastitis and further selection of proper antibiotic has to be done after antibiotic sensitivity test. 


\section{Acknowledgement}

The author wish to express sincere thanks to Dr K. Satish Kumar, Professor \&University Head, Department of Veterinary Medicine, College of Veterinary Science, PVNR TVU and other staff for providing the facilities and assisting successful completion of this case study.

\section{References}

BarkemaHW., Schukken YH, Lam TJGM, Beiboer ML, Benedictus $G$ and Brand A. 1999. Management practices associated with the incidence rate of clinical mastitis. J. Dairy Sci. 82:16431654.

Bramley AJ. 1992. Mastitis. In: Bovine Medicine - Diseases and Husbandry of Cattle (Ed. A. H.

Gallin JI., Goldstein IM and Snyderman R. 1992. Inflammation: Basic Principles and Clinical Correlates. 2nd ed. Raven Press. New York, NY.

Ganguly S. 2014. A comprehensive and illustrious review on clinical and diagnostic aspects of mastitis infection in high yielding lactating cows. World J. Pharma. Res. 3(9): 352- 360.

Halasa T, Huijps K, Østerås O, and Hogeveen $\mathrm{H}$, "Economic effects of bovine mastitis and mastitis management: a review,"Vet. Quarterly, vol. 29, no. 1, pp. 18-31, 2007.

Politis I, Hidiroglou N, White JH, Gilmore JA, Williams SN, Scherf $\mathrm{H}$ and Frigg M. 1996. Effects of vitamin $\mathrm{E}$ on mammary and blood leukocyte function with emphasis on chemotaxis in periparturient dairy cows. Am. J. Vet. Res.57:468-471.

Radostits OM, Gay CC, Hinchcliff K W and Constable PD. (2007). Mastitis in: Veterinary Medicine: Textbook of diseases of cattle, sheep, pigs, goats and horses 10th edition. Balliere Tindall, London. pp. 674-762.

Rajala-Schultz PJ, Grohn YT, McCulloch CE, and Guard CL, "Effects of clinical mastitis on milk yield in dairy cows," $J$. Dairy Science, vol. 82, no. 6, pp. 12131220, 1999.

Sharif A, Umer M and Muhammad G 2009. Mastitis control in dairy production. $J$. Agric. Soc. Sci. 5:102-105.

Sharif A., Umer M and Muhammad G. 2009. Mastitis control in dairy production. J. Agric. Soc. Sci. 5:102-105.

Sharma N., Gautam A, Upadhyay SR, Hussain K, Soodan JS and Gupta SK. 2006. Role of antioxidants in udder health: a review. Indian J. Field Vet. 2(1):73-76.

Smith KL., TodhunterDA and Schoenberger PS. 1985. Environmental mastitis: cause, prevalence, prevention. J. Dairy Sci. 68:1531.

\section{How to cite this article:}

Babji. B. R., G. Abhinav Kumar Reddy, G. Ambica and Ranjith Kumar. S. 2020. A Case Study of Clinical Mastitis in a Cow. Int.J.Curr.Microbiol.App.Sci. 9(05): 1759-1764. doi: https://doi.org/10.20546/ijcmas.2020.905.198 